Journal of Bangladesh Chemical Society, Vol. 24(2), 143-157, 2011.

DOI: $10.3329 /$ jbcs.v24i2.9703

\title{
VOLUMETRIC STUDIES OF ALCOHOLS IN WATER AND AQUEOUS MICELLE SOLUTIONS OF CETYLTRIMETHYLAMMONIUM BROMIDE
}

\author{
T. PARVIN*, M. ALAUDDIN and M. ROKONUZZAMAN ${ }^{1}$
}

Department of Applied Chemistry and Chemical Technology, Islamic University, Kushtia 7003,

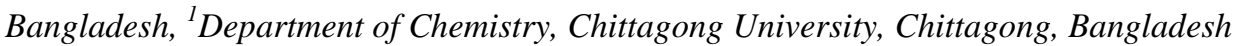

\begin{abstract}
The volumetric properties of 1-propanol, cyclohexanol and butoxyethanol in water and $\mathrm{CTAB}$ water mixtures have been studied. The apparent molar volumes of 1propanol, cyclohexanol and butoxyethanol in water and in aqueous solutions of CTAB were determined from density data. The partial molar volumes of the alcohols in water and aqueous micelle solutions at infinite dilution, $\bar{V}_{2}^{0}$ (mic) were obtained from apparent molar volume data and compared with the corresponding values. The standard partial molar expansibilities, $\bar{E}_{2}^{0}$ (mic) of the solubilizates were evaluated from $\bar{V}_{2}^{0}$ (mic) data at various temperatures. The volumetric studies of alcohols in $\mathrm{CTAB}$ micelles indicate that alcohols on the average are preferentially solubilized in the palisade layer of the micelle and increasing amount of each is transferred more deep into the palisade layer of the micelle with increasing surfactant concentration and temperature. The results of standard partial molar volume, $\bar{V}_{2}^{0}$ and standard partial molar expansibilities, $\bar{E}_{2}^{0}$ are reported and discussed.
\end{abstract}

\section{Introduction}

Surfactants are widely used in a variety of industrial and commercial applications. A number of investigations ${ }^{1-3}$ have been carried out in recent years with view of improving our understanding on the structural properties of micelles formed by surfactants in water. In aqueous solutions, ionic surfactants generally form spherical micelles just above the $\mathrm{CMC}$ and, some, further associate to form rod-like micelles at higher concentration. There is report that presence of different solutes in surfactant solution induces very marked changes in the micellar properties. The addition of any solute in the micellar system may change the size and shape of micelle considerably.

It is well known that solubility of predominantly hydrophobic molecule in aqueous solution is enhanced by the addition of surfactants to the solution. This phenomenon of increasing solubility of apolar molecules in micellar solutions, known as solubilization, constitutes the basis on which surfactant find useful applications in many biological, pharmaceutical and industrial systems. The process of solubilization of hydrophobic solutes in micellar system is intimately associated with the properties of the micelle as well as the properties of the solubilized species. With incorporation of increasing amount of nonpolar material into inner core, a normal micelle in aqueous medium may become more and more asymmetric, eventually becoming lamellar in shape. It has been reported that solubilization of different solutes in CTAB induces very marked changes in the

*To whom correspondence should be made. E-mail: t.parvin@yahoo.com 
micellar shape. ${ }^{4-9}$ A micellar transition of CTAB has been reported in the concentration range from 0.05 to $0.34 \mathrm{~mol} \mathrm{~kg}^{-1}$ by using viscosity, Rayleigh light scattering ${ }^{81} \mathrm{Br} \mathrm{NMR}$, SAXS, and other techniques..$^{10-16}$ Vikholm et al ${ }^{17}$. examined the shape transition in the aqueous phase of the system hexadecyltrimethylammonium bromide-hexanol-water by viscosity, conductivity and ultrasonic velocity measurements. They suggest a shape transition from spherical to larger rod or disk like micelles as well as the breakdown of the large aggregate to spherical micelle depending upon the amount of hexanol solubilized by micelles.

The aim of the present work is to investigate the ternary systems surfactant-water-alcohol to have an understanding on the solubilization behavior of the alcohols and their interactions with surfactant forming the mixed micelle. We report here the volumetric properties of 1-propanol (1-PrOH), cyclohexanol and 2-Butoxyethanol solubilized in water and aqueous micelle solution of CTAB of different concentration at different temperature. The results are interpreted in terms of approximate location of the solubilizate in the micellar aggregates, possible changes in the size and shape of the micelle and the interactions between the solubilizate and the surfactant species within the micelle.

\section{Experimental}

Cetyltrimethylammonium bromide, $\mathrm{CH}_{3}\left(\mathrm{CH}_{2}\right)_{15} \mathrm{~N}^{+}\left(\mathrm{CH}_{3}\right)_{3} \mathrm{Br}^{-}$(CTAB) was obtained from E. Merck, Darmstadt (Germany) and its purity was > 99\%. 1-propanol, and cyclohexanol were obtained from Merck (Germany) and their purity was better than $99 \%$. 2-Butoxyethanol (BE) was obtained from Aldrich Chemical Company Limited and its purity was $>99 \%$. All these compounds were reagent grade and used without further purification. Water used in this experiment was double distilled. Aqueous stock solutions of CTAB of different concentrations were prepared and used as mixed solvent in volumetric studies. All solutions were prepared by weight and their concentrations are expressed as the number of solute moles per $\mathrm{kg}$ of solvent. Solubilizate in the mixed solvent were stirred for several hours to ensure the equilibrium condition to be reached.

The apparent molar volume, of liquid solutions were calculated from the relation

$$
\phi_{v}=\frac{1000}{m d d_{0}}\left(d_{0}-d\right)+\frac{M}{d}
$$

where $\mathrm{m}$ is the molality of the solution, $\mathrm{M}$ is the molar mass of the solute, $\mathrm{d}$ is the density of the solution and $d_{o}$ is the density of the solvent. Densities of solutions were measured in a calibrated pycnometer having $25 \mathrm{ml}$ capacity. The temperatures of measurements were accurate to $\pm 0.1^{\circ} \mathrm{C}$. The concentration dependence of $\phi_{v}$ of 1-propanol, cyclohexanol and BE in water and in aqueous solutions of CTAB as a function of surfactant and solubilizate concentration and temperature have been estimated from density data. All measurements were carried out at $30,35,40$ and $45^{\circ} \mathrm{C}$. 
The partial molar volumes of 1-propanol, cyclohexanol and BE in water and in CTAB solutions at infinite dilution $\bar{V}_{2}^{0}\left(\phi_{v}^{0}=\bar{V}_{2}^{0}\right)$ were obtained from the plots of $\phi_{\mathrm{v}}$ versus molality, of the relation $\phi_{v}=\phi_{v}^{0}+b m$ by extrapolating it to $\mathrm{m}=0$.

The standard partial molar expansibilities, $\bar{E}_{2}^{0}$ of 1-propanol, cyclohexanol and butoxyethanol (BE) in water and aqueous micelle solutions of CTAB of different concentration, obtained from the temperature dependence of $\bar{V}_{2}^{0}$.

\section{Results and Discussion}

\section{Propanol in water and CTAB- water systems}

The variation of $\phi_{\mathrm{v}}$ of 1-propanol in water in the concentration range $0.50-3.0 \mathrm{~mole} / \mathrm{kg}$ at different temperatures is shown in Fig. 1. The results show that the apparent molar volume of 1-propanol initially slightly decreases and then remains almost invariant with further increase in the concentration of 1-propanol at all temperature studied

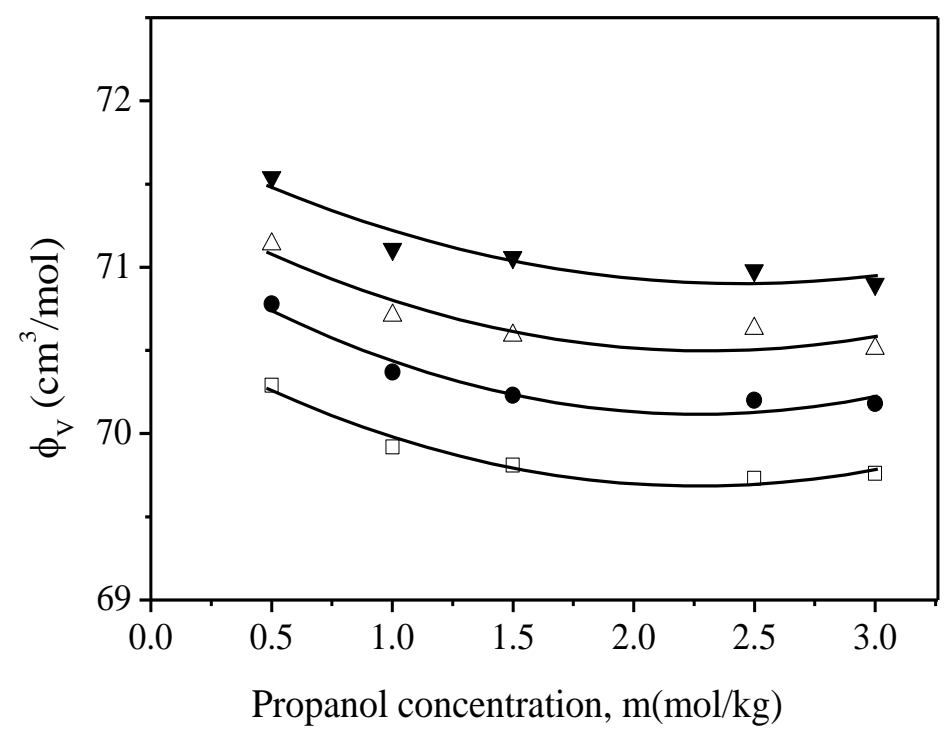

Fig 1. Apparent molar volume of 1-propanol as a function of its molality in water at $\square 30^{\circ}, \bullet 35^{\circ}$, $\triangle 40^{\circ}$ and $\boldsymbol{\nabla} 45^{\circ} \mathrm{C}$.

The variation of $\phi_{\mathrm{v}}$ of 1-propanol in $0.05 \mathrm{~m}$ and $0.35 \mathrm{~m}$ CTAB solutions at different temperatures is shown in Fig. 2 and 3. It appears that the variation of $\phi_{\mathrm{v}}$ of 1-propanol in CTAB solution of different concentrations shows the similar trend in variation as observed for 1-propanol in water. In both cases, $\phi_{\mathrm{v}}$ of propanol increases with increasing CTAB content in water at different temperature. A close examination of Fig. 1-3 indicate that the apparent molar volumes of 1-propanol in CTAB-water mixtures become 
significantly larger than its value in water and the magnitude of $\phi_{v}$ rises with increasing CTAB concentration in water.

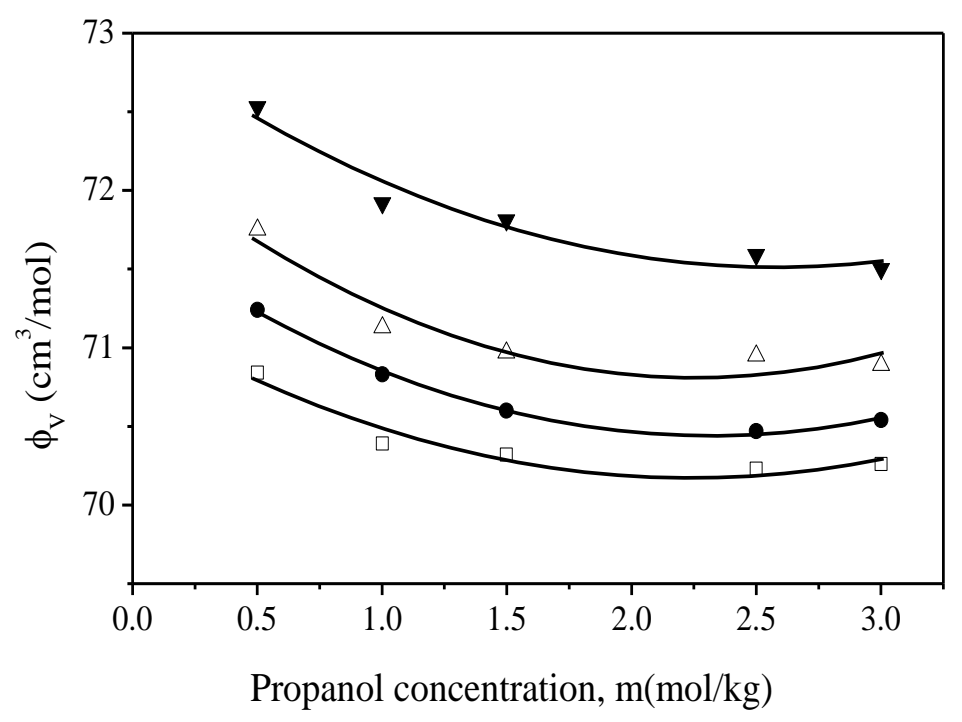

Fig 2. Apparent molar volume of 1-propanol as a function of its molality in $0.05 \mathrm{~m} \mathrm{CTAB}$ water solution at $\square 30^{\circ}, \bullet 35^{\circ}, \Delta 40^{\circ}$ and $\boldsymbol{\nabla} 45^{\circ} \mathrm{C}$.

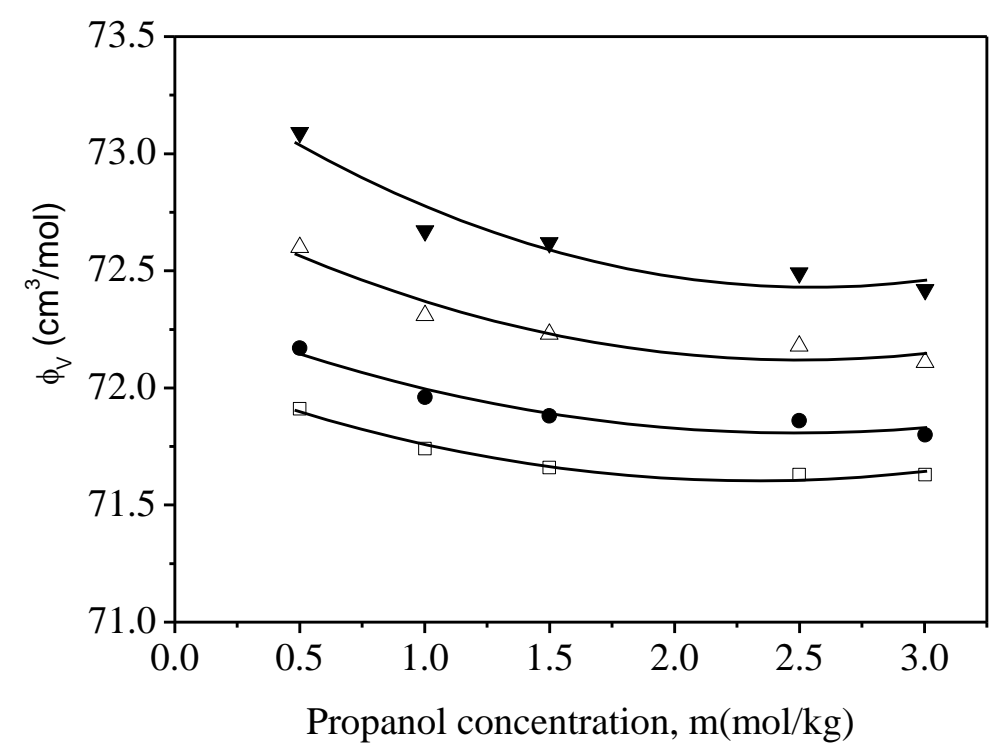

Fig 3. Apparent molar volume of 1-propanol as a function of its molality in $0.35 \mathrm{~m}$ CTAB water solution at $\square 30^{\circ}, \bullet 35^{\circ}, \Delta 40^{\circ}$ and $\boldsymbol{\nabla} 45^{\circ} \mathrm{C}$. 
The initial decrease of $\phi_{v}$ of 1-Propanol in water indicates that 1-Propanol undergoes hydrophobic hydration in the aqueous phase at low 1-Propanol concentration. On increasing the 1-Propanol concentration this hydrophobic hydration decreases and change over to hydrophobic interaction thereby showing no significant change in volume and this observation is apparent for all temperature studied.

The observed trends in the variation of volume of 1-Propanol in CTAB-water system is similar to that observed for 1-Propanol in water, but the apparent molar volumes of 1Propanol becomes little larger in the presence of CTAB and the difference between $\phi_{v}$ of 1-Propanol in water and in $\mathrm{CTAB}$ solution increases with increasing surfactant concentration and temperature. This increase in volume is probably the results of hydrophobic dehydration of 1-Propanol and that an increasing proportion of 1-Propanol is transferred into CTAB micelles. It appears that like 1-Propanol-water system, the $\phi_{v}$ of 1-Propanol dissolved in CTAB solutions of different molalities remain almost invariant upon increasing the 1-Propanol concentration. It is expected that mixed micelles are formed between 1-propanol and CTAB. The viscosity measurements have previously

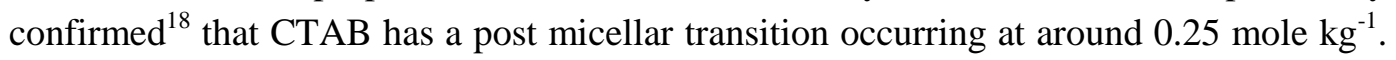
The invariance of $\phi_{v}$ of 1-Propanol with increasing concentration in both the surfactant solutions $(0.05 \mathrm{~m}, 0.35 \mathrm{~m})$, indicate that the shape of CTAB micelle does not affect the solubilization process of 1-Propanol in the micellar aggregates.

\section{Butoxyethanol in water and CTAB water systems}

Fig.4 shows the variation of $\phi_{\mathrm{v}}$ of BE in water as a function of its molality. The results show that the apparent molar volume initially decreases and then increases with increasing concentration of BE. The variation of $\phi_{\mathrm{v}}$ of BE in $0.05 \mathrm{~m}$ and $0.3 \mathrm{~m} \mathrm{CTAB-}$ water systems as a function of its molality is shown in Fig.5 and 6. It appears that the variation of $\phi_{\mathrm{v}}$ of BE in CTAB solution of two different concentrations show a general trend in which the apparent molar volumes of BE initially decreases with an increase in $\mathrm{BE}$ content and then increases upon increasing the concentration of BE. A minimum in $\phi_{\mathrm{v}}$ is observed at $0.5 \mathrm{~mol} \mathrm{~kg} \mathrm{~kg}^{-1}$ of BE dissolved in two different surfactant solutions. The increment in $\phi_{\mathrm{v}}$ with increasing the BE molality becomes less pronounced in solution of higher $\mathrm{CTAB}$ concentration and it becomes almost invariant in $0.30 \mathrm{~m}$ CTAB with increasing BE content beyond $1.0 \mathrm{~mol} \mathrm{~kg}^{-1}$. 


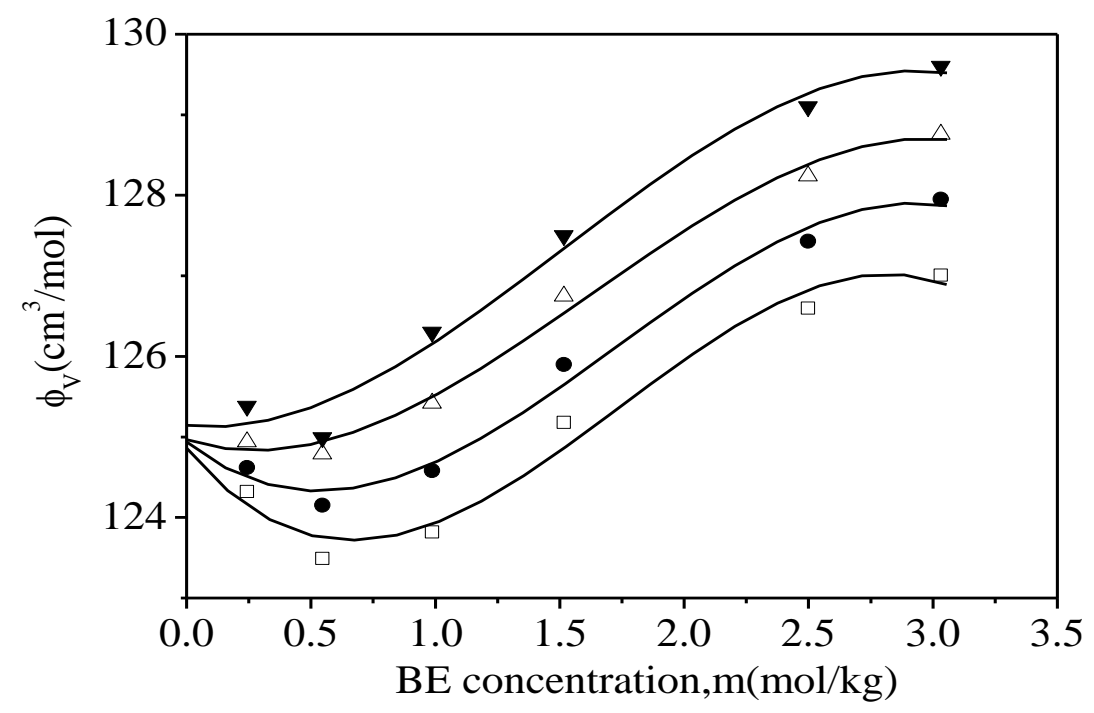

Fig 4. Apparent molar volume of $\mathrm{BE}$ as a function of its molality in water at $\square 30^{\circ}, \bullet 35^{\circ}, \Delta 40^{\circ}$ and $\boldsymbol{\nabla} 45^{\circ} \mathrm{C}$.

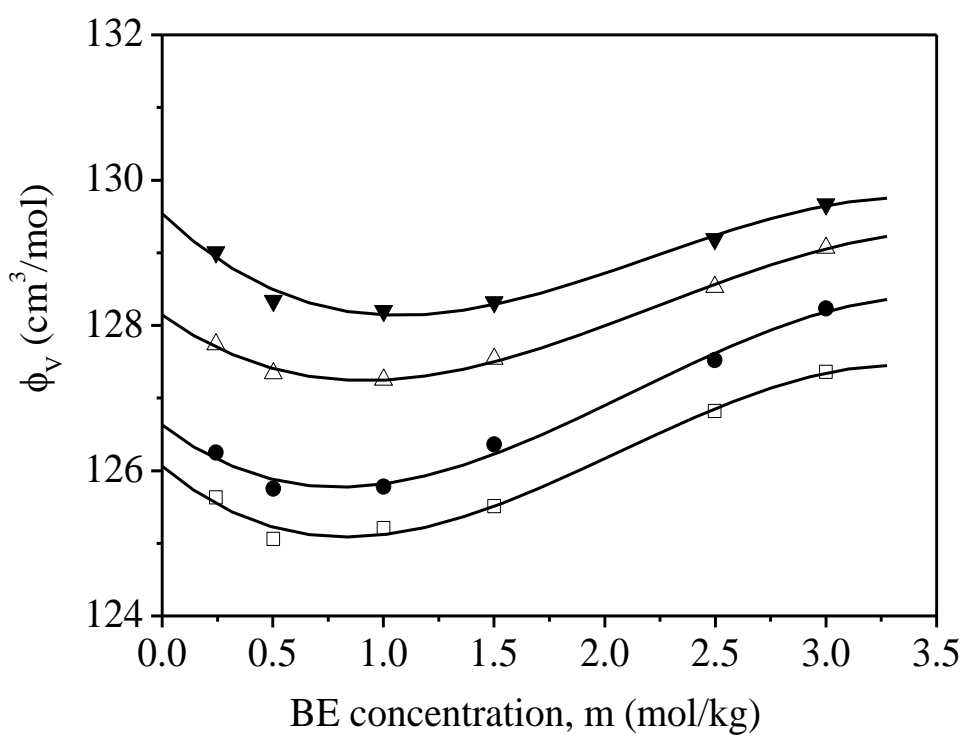

Fig. 5. Apparent molar volume of $\mathrm{BE}$ as a function of its molality in $0.05 \mathrm{~m}$ CTAB water solution at $\square 30^{\circ}, \bullet 35^{\circ}, \Delta 40^{\circ}$ and $\nabla 45^{\circ} \mathrm{C}$. 


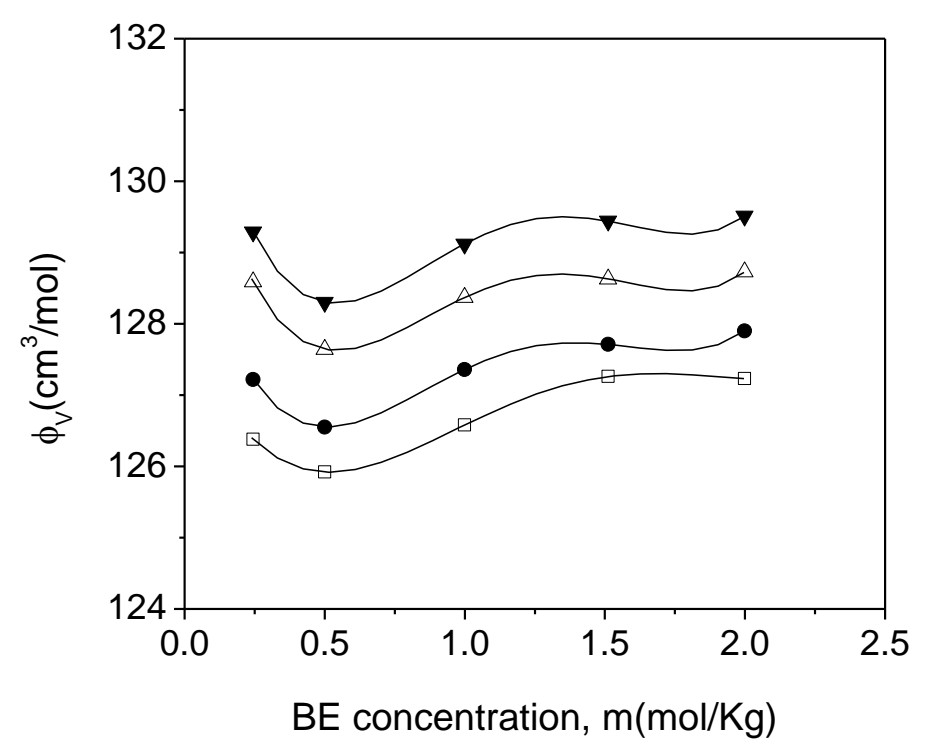

Fig. 6. Apparent molar volume of $\mathrm{BE}$ as a function of its molality in $0.30 \mathrm{~m} \mathrm{CTAB}$ solution at $\square 30^{\circ}, \bullet 35^{\circ}, \Delta 40^{\circ}$ and $\nabla 45^{\circ} \mathrm{C}$.

The initial decrease of $\phi_{v}$ of BE in water with a minimum at $0.60 \mathrm{~m}$ (Fig.4) indicates that $\mathrm{BE}$ under goes a strong hydrophobic hydration in the aqueous phase at low BE concentration. On increasing the BE concentration this hydrophobic hydration decreases, the hydrophobic interaction occurs and $\mathrm{BE}$ undergoes some microphase transition through hydrophobic interaction. The minimum observed at $0.60 \mathrm{~m}$ in the $\phi_{v}$ vs. $\mathrm{m}$ graph becomes less profound and shifts to low concentration with increasing temperature suggest that the hydrophobic interaction increases with increasing temperature thereby enhancing the microphase transition.

The observed trends in the variation of volume of $\mathrm{BE}$ in $\mathrm{CTAB}$-water systems is similar to that for $\mathrm{BE}$ in water, but the volumes of $\mathrm{BE}$ becomes larger in the presence of $\mathrm{CTAB}$. This increase of volume is probably the results of hydrophobic dehydration of $\mathrm{BE}$ and that an increasing proportion of $\mathrm{BE}$ is transferred into CTAB micelles. It appears that the observed minimum in volume of $\mathrm{BE}$ is simply shifted to lower concentration of $\mathrm{BE}$ from 0.60 to $0.50 \mathrm{~mol} \mathrm{~kg}^{-1}$ in the presence of $0.30 \mathrm{~m} \mathrm{CTAB}$ (Fig. 5 and 6). This indicates that the microphase transition of BE is enhanced due to the presence of CTAB. Fig. 6 and 7 shows that the increment in $\phi_{v}$ of $\mathrm{BE}$ dissolved in $\mathrm{CTAB}$ solutions becomes less pronounced in solution of higher $\mathrm{CTAB}$ concentration and $\phi_{\nu}$ becomes almost invariant in $0.30 \mathrm{~m} \mathrm{CTAB}$ upon increasing the $\mathrm{BE}$ concentration above $1.0 \mathrm{~mol} \mathrm{~kg}^{-1}$. It is expected that mixed micelles are formed between $\mathrm{BE}$ and $\mathrm{CTAB}$ and that $\mathrm{BE}$ is increasingly transferred 
to the micellar phase upon increasing the amount of $\mathrm{BE}$ in the system forming mixed micelle. The invariance of $\phi_{v}$ of BE with its concentration above $1.0 \mathrm{~m}$ in $0.30 \mathrm{~mol} \mathrm{~kg}^{-}$ ${ }^{1} \mathrm{CTAB}$ indicate that transfer of $\mathrm{BE}$ becomes less favorable in rod-like micelles formed by $\mathrm{CTAB}$ at higher concentration.

\section{Cyclohexanol in water and CTAB-Water systems}

The apparent molar volumes of cyclohexanol were found to be almost invariant over the concentration range studied (Fig. 7 ). The constancy of $\phi_{\mathrm{v}}$ of cyclohexanol in water with its concentration suggests that cyclohexanol does not have any significant effect the structural properties of water.

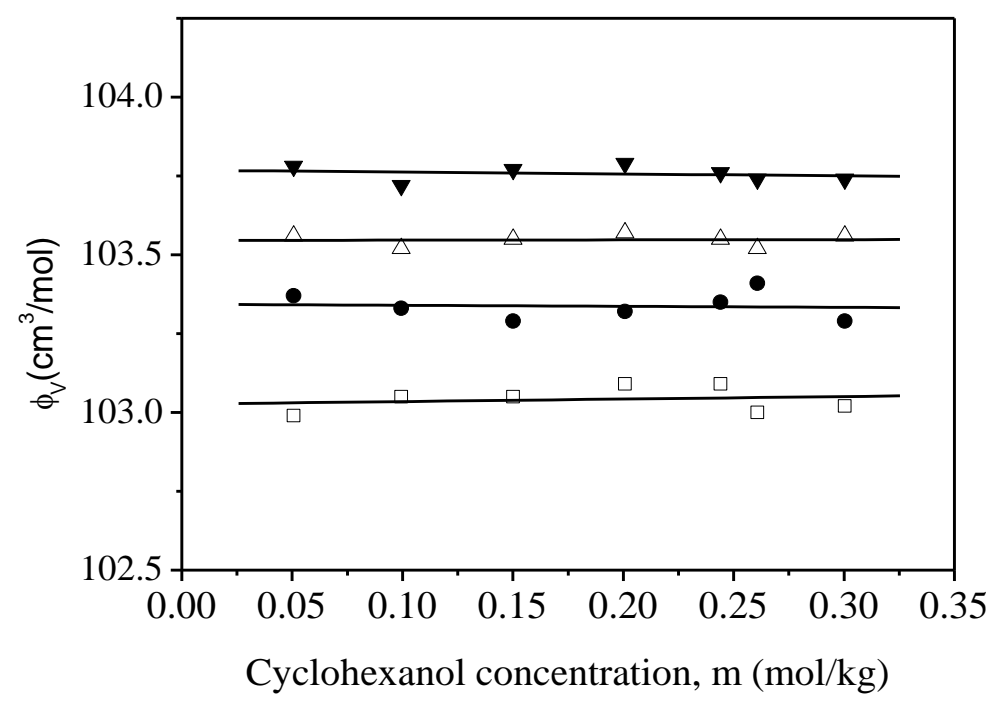

Fig. 7. Apparent molar volume of cyclohexanol as a function of its molality in water at $\square 30^{\circ}$, - $35^{\circ}, \Delta 40^{\circ}$ and $\boldsymbol{\nabla} 45^{\circ} \mathrm{C}$.

Fig. 8 and 9 shows the variation of apparent molar volumes, $\phi_{\mathrm{v}}$ of cyclohexanol dissolved in 0.05 and $0.10 \mathrm{~m} \mathrm{CTAB} \mathrm{solutions.} \mathrm{It} \mathrm{appears} \mathrm{that} \mathrm{the} \phi_{\mathrm{v}}$ of cyclohexanol dissolved in CTAB solutions of different concentrations remains invariant similar to that observed for cyclohexanol in water. This suggests that size and shape of the micelle do not appreciably affect the solubilization process of cyclohexanol in the micellar aggregates. However, a relatively higher values of $\phi_{\mathrm{v}}$ of cyclohexanol in CTAB solutions than its value in water indicate that cyclohexanol experience some hydrocarbon-like environment in the surfactant solution. 


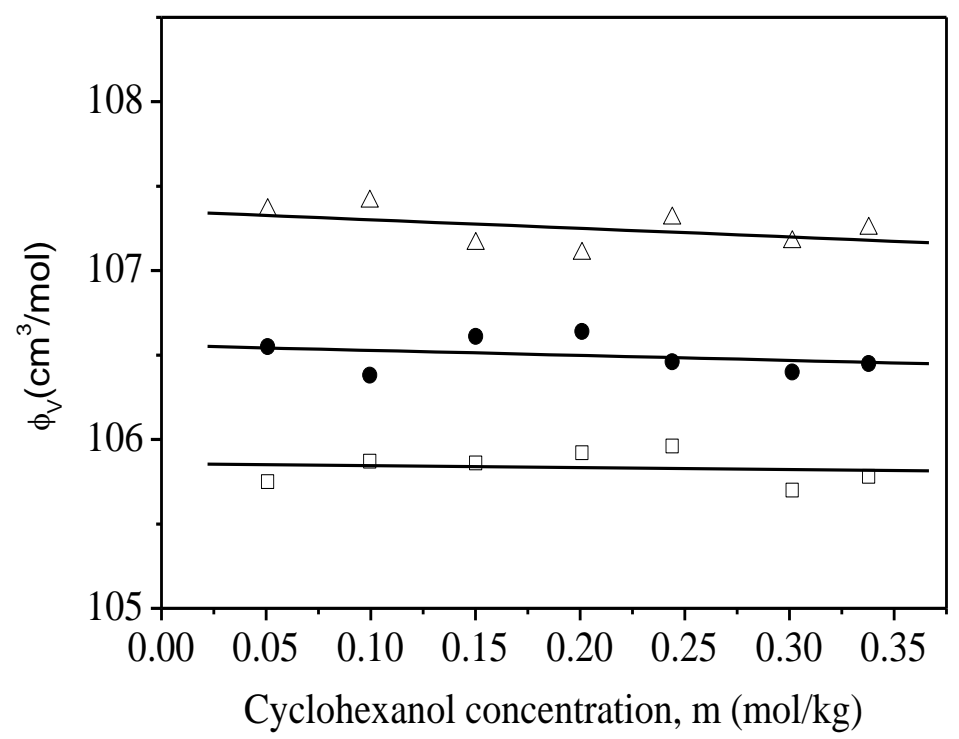

Fig. 8. Apparent molar volume of cyclohexanol as a function of its molality in $0.05 \mathrm{~m}$ CTAB water solution at $\square 35^{\circ}, \bullet 40^{\circ}$ and $\Delta 45^{\circ} \mathrm{C}$.

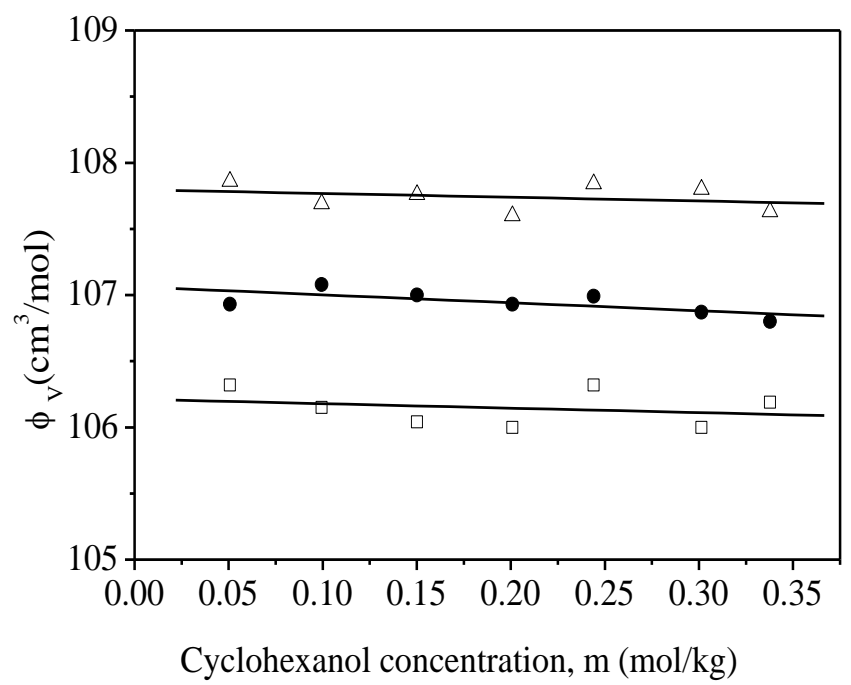

Fig. 9. Apparent molar volume of cyclohexanol as a function of its molality in $0.10 \mathrm{~m}$ CTAB water solution at $\square 35^{\circ}, \bullet 40^{\circ}$ and $\Delta 45^{\circ} \mathrm{C}$. 


\section{Standard partial molar volumes}

The partial molar volumes, $\bar{V}_{2}^{0}$ of 1-propanol, cyclohexanol and BE in water and in CTAB solutions at infinite dilution, $\phi_{v}^{o}=\bar{V}_{2}^{0}$ were obtained from the plots of $\phi_{\mathrm{v}}$ versus molality by extrapolating it to $\mathrm{m}=0$ by using a weighted least-squares method to fit the experimental data to the assumed relation $\phi_{v}=\phi_{v}^{o}+b m$. Derived values of $\bar{V}_{2}^{0}$ for each solubilizate in water and in CTAB-water mixed solvent above the CMC at 30, 35, 40, and $45^{\circ} \mathrm{C}$ temperature are shown in Table 1 . The values of $\bar{V}_{2}^{0}$ (mic) for the solubilizates in aqueous micelle solution of $\mathrm{CTAB}$ of different concentration increases with increasing temperature. In all cases $\phi_{\mathrm{v}}\left(45^{0}\right)>\phi_{\mathrm{v}}\left(40^{\circ}\right)>\phi_{\mathrm{v}}\left(35^{\circ} \mathrm{C}\right)$. Results of several studies indicate that micelles are highly hydrated. Also micelles are considered to be the porous clusters of surfactant, which provide opportunities for water to penetrate into the micellar aggregates. The CTAB micelle is expected to be highly hydrated and this is supported by our experimental observation that $\phi_{\mathrm{v}}$ increases with increasing temperature. This implies that an increase in temperature can cause a further desolvation of the micelles and their counterions thus providing a hydrocarbon-like environment for the solubilizates.

Table 1. Partial molar volume of alcohols at infinite dilution $\bar{V}_{2}^{0}$ in water and CTAB- water mixture at $30^{\circ}, 35^{\circ}, 40^{\circ}$, and $45^{\circ} \mathrm{C}$.

\begin{tabular}{|c|c|c|c|c|c|}
\hline \multirow[b]{2}{*}{ Solute } & \multirow{2}{*}{$\begin{array}{l}\text { Solvent } \\
\text { System }\end{array}$} & \multicolumn{4}{|c|}{$\bar{V}_{2}^{0} \quad\left(\mathrm{~cm}^{3} \mathrm{~mol}^{-1}\right)$} \\
\hline & & $30^{0} \mathrm{C}$ & $35^{0} \mathrm{C}$ & $40^{0} \mathrm{C}$ & $45^{0} \mathrm{C}$ \\
\hline \multirow{3}{*}{ 1-Propanol } & Water & 70.63 & 71.14 & 71.45 & 71.82 \\
\hline & $0.05 \mathrm{~m}$ CTAB & 71.20 & 71.72 & 72.24 & 72.97 \\
\hline & $0.35 \mathrm{~m} \mathrm{CTAB}$ & 72.08 & 72.34 & 72.81 & 73.37 \\
\hline \multirow{4}{*}{$\mathrm{BE}$} & Water & 124.86 & 124.93 & 124.96 & 125.14 \\
\hline & $0.05 \mathrm{~m} \mathrm{CTAB}$ & 126.06 & 126.62 & 128.14 & 129.53 \\
\hline & $0.30 \mathrm{~m} \mathrm{CTAB}$ & 127.20 & 127.91 & 129.6 & 130.37 \\
\hline & n-heptane $e^{19}$ & 137.27 & 138.37 & 139.37 & 140.33 \\
\hline \multirow{4}{*}{ Cyclohexanol } & Water & & 103.34 & 103.55 & 103.77 \\
\hline & $0.05 \mathrm{~m} \mathrm{CTAB}$ & & 105.86 & 106.56 & 107.35 \\
\hline & $0.10 \mathrm{~m} \mathrm{CTAB}$ & & 106.21 & 107.06 & 107.80 \\
\hline & n-heptane $\mathrm{e}^{20}$ & 114.20 & 115.00 & 115.70 & \\
\hline
\end{tabular}

A comparison of $\bar{V}_{2}^{0}$ (mic) data for 1-Propanol in aqueous micelle solutions of CTAB with its value in water shows that $\bar{V}_{2}^{0}$ (mic) is not much different from $\bar{V}_{2}^{0}$ (aq). This indicates that 1-Propanol experience some aqueous like environment in the surfactant solution and is thus expected to be located in the hydrated surface region of the micelle and undergoes a strong hydrophilic interaction between the solubilizate and the 
micellized surfactant. It however, appears that, $\bar{V}_{2}^{0}$ (mic) is little higher than $\bar{V}_{2}^{0}(\mathrm{aq})$. Further, it appears that $\bar{V}_{2}^{0}$ (mic) increases with increasing surfactant concentration and temperature. Reed et al. ${ }^{21}$ have reported the extensive exposure of methylene groups of CTAB to water. This suggests that, the increasing amount of 1-Propanol is dispersed in the micellar aggregates upon increasing the surfactant concentration, temperature and are preferentially solubilized in the palisade layer close to the micellar surface.

A comparison of partial molar volume, $\bar{V}_{2}^{0}$ (mic) for BE in aqueous micelle solutions of CTAB with its value in water and heptane show that $\bar{V}_{2}^{0}$ (mic) $<\bar{V}_{2}^{0}$ (heptane). Table 1 shows that this value in micelle solution is about $11 \mathrm{~cm}^{3} \mathrm{~mol}^{-1}$ smaller than in pure heptane. This can be attributed to strong hydrophilic interaction between the solubilizate and micellized surfactant like 1-Propanol. A close agreement between $\bar{V}_{2}^{0}$ (mic) and $\bar{V}_{2}^{0}$ (aq) for $\mathrm{BE}$ indicate that $\mathrm{BE}$ experience some aqueous-like environment in the micellar systems and that the local environment of $\mathrm{BE}$ in the micelle is quite different from that found in organic environment such as heptane or core of the micelle. It, however, appears that $\bar{V}_{2}^{0}$ (mic) increases with increasing $\mathrm{CTAB}$ concentration. This suggests that $\mathrm{BE}$ form mixed micelle with $\mathrm{CTAB}$ by short penetration into the micellar aggregates, and an increasing amount of $\mathrm{BE}$ is transferred more deep into the palisade layer of the micelle with increasing temperature and surfactant concentration.

The $\bar{V}_{2}^{0}$ data for cyclohexanol in micellar, hydrocarbon, and aqueous solvents at 35, 40, and $45^{\circ} \mathrm{C}$ show that $\bar{V}_{2}^{0}$ (mic) $<\bar{V}_{2}^{0}$ (n-heptane). Table 1 shows that this value in micellar phase is about $10 \mathrm{~cm}^{3} \mathrm{~mol}^{-1}$ smaller than in n-heptane. This is likely to be due to strong hydrophilic interaction between the head groups of the alcohol and the surfactant monomers in the micellar aggregates. The relatively close agreement between $\bar{V}_{2}^{0}$ (mic) and $\bar{V}_{2}^{0}$ (aq) implies that cyclohexanol molecule is in an aqueous-like environment in the surfactant solution and thus solubilized in the hydrated surface region of the micelle. However, the values of $\bar{V}_{2}^{0}$ (mic) are invariably little larger than $\bar{V}_{2}^{0}(\mathrm{aq})$. This suggests that the cyclohexanol molecule is preferentially solubilized in the palisade layer of the micelle, probably with hydrophobic part solubilized in the palisade layer while the relatively polar $-\mathrm{OH}$ group is directed towards the surrounding water. Values of $\bar{V}_{2}^{0}$ (mic) for cyclohexanol in $\mathrm{CTAB}$ micelle remain almost invariant with increasing micelle concentration indicating a similar type of environment of cyclohexanol in different surfactant solutions at a given temperature.

The standard partial molar expansibilities, $\bar{E}_{2}^{0}\left(\bar{E}_{2}^{0}=d \bar{V}_{2}^{0} / d T\right)$ of 1-propanol, butoxyethanol (BE) and cyclohexanol in water and aqueous micelle solutions of CTAB of 
different concentration, obtained from the temperature dependence of $\bar{V}_{2}^{0}$, show a linear dependence of $\bar{V}_{2}^{0}$ with temperature for each solubilizate (Fig.10-12). The values of $\bar{V}_{2}^{0}$ for the solubilizates increase with temperature i.e. $\bar{E}_{2}^{0}$ values are positive. The values of $\bar{E}_{2}^{0}$ of solubilizates in different solvent systems are reported in Table 2.

Table 2. Standard partial molar expansibilities, $\bar{E}_{2}^{0}$ of 1-Propanol, BE and cyclohexanol in water and in different CTAB solutions.

\begin{tabular}{|c|c|c|}
\hline \multirow{3}{*}{ Solute } & Solvent system & $\begin{array}{c}\bar{E}_{2}^{0}, \\
\mathrm{~cm}^{3} \mathrm{~mol}^{-1} \mathrm{~kg}^{-1}\end{array}$ \\
\hline \multirow{3}{*}{ 1-Propanol } & Water & 0.078 \\
\cline { 2 - 3 } & $0.05 \mathrm{~m} \mathrm{CTAB}$ & 0.117 \\
\cline { 2 - 3 } & $0.35 \mathrm{~m} \mathrm{CTAB}$ & 0.087 \\
\hline \multirow{3}{*}{ BE } & Water & 0.017 \\
\cline { 2 - 3 } & $0.05 \mathrm{~m} \mathrm{CTAB}$ & 0.239 \\
\cline { 2 - 3 } & $0.30 \mathrm{~m}$ CTAB & 0.224 \\
\hline \multirow{3}{*}{ Cyclohexanol } & n-heptane & 0.204 \\
\cline { 2 - 3 } & water & 0.043 \\
\cline { 2 - 3 } & 0.05 mCTAB & 0.149 \\
\cline { 2 - 3 } & $0.10 \mathrm{mCTAB}$ & 0.159 \\
\cline { 2 - 3 } & n-heptane & 0.156 \\
\hline
\end{tabular}

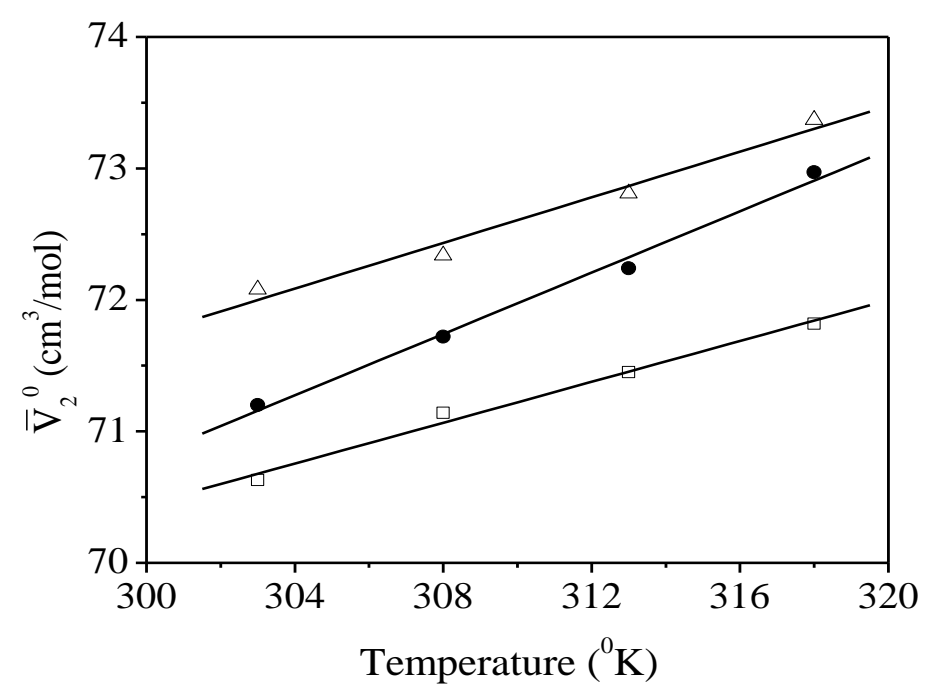

Fig. 10. Partial molar volume of 1-popanol as a function of temperature in $\square$ Water, $\bullet 0.05 \mathrm{~m}$ CTAB and $\Delta 0.35 \mathrm{~m}$ CTAB solutions. 


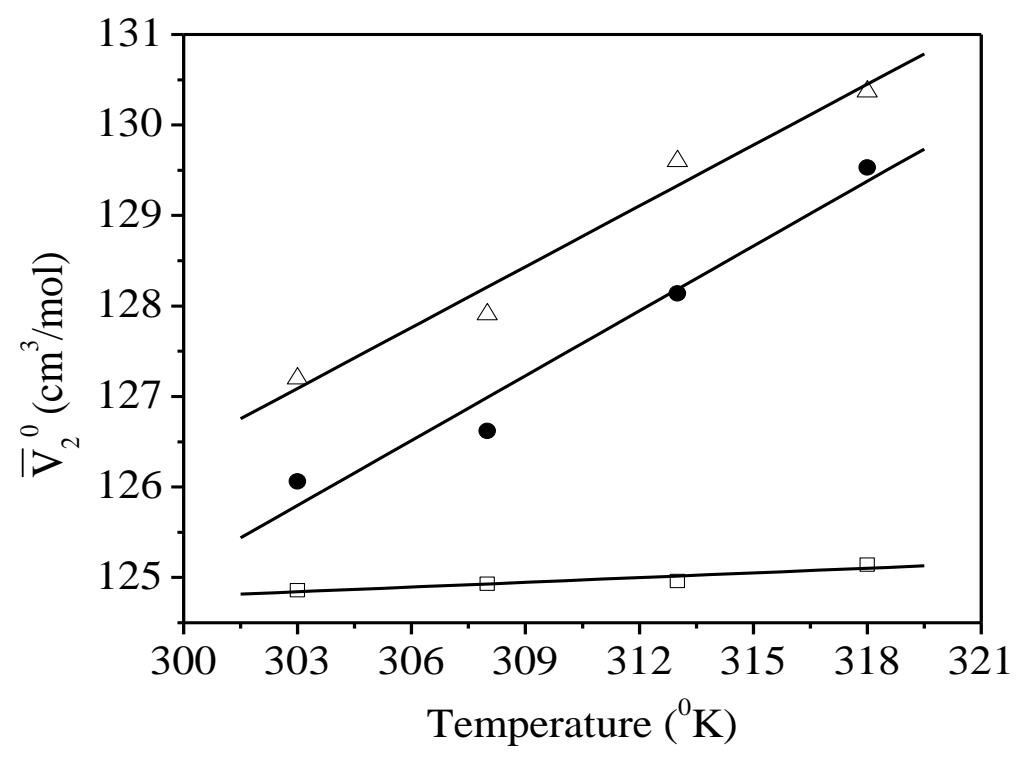

Fig. 11. Partial molar volume of $\mathrm{BE}$ as a function of temperature in $\square$ Water, $\bullet 0.05 \mathrm{~m}$ CTAB and $\Delta 0.30 \mathrm{~m}$ CTAB solutions.

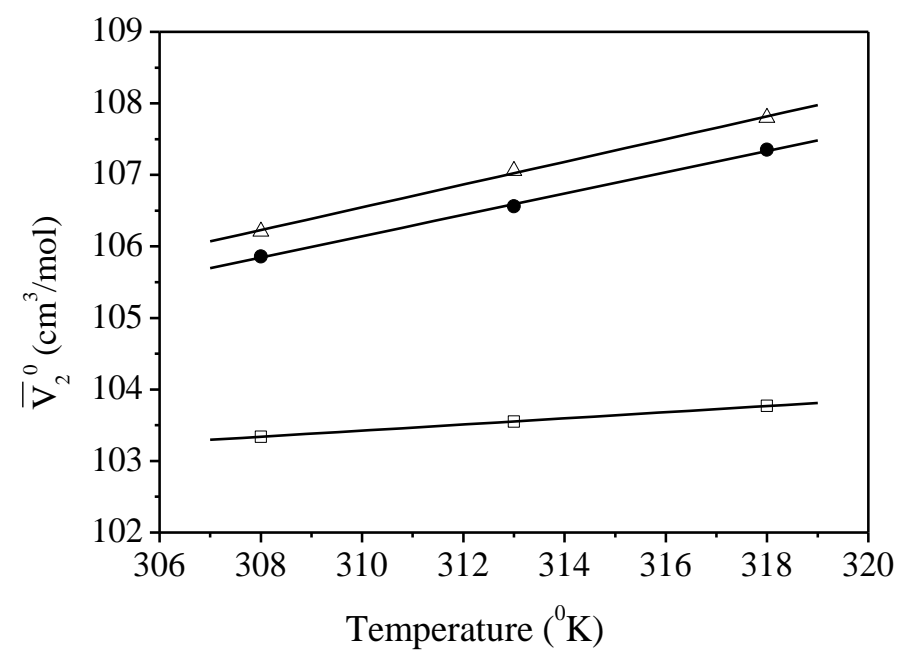

Fig. 12. Partial molar volume of cyclohexanol as a function of mperature in $\square$ Water, $\bullet 0.05 \mathrm{~m}$ CTAB and $\Delta 0.10 \mathrm{~m} \mathrm{CTAB}$ solutions. 
The temperature dependence of $\bar{V}_{2}^{0}$ gives a direct measure of the partial molar expansibility, $\bar{E}_{2}^{0}$, at infinite dilution. The expansibility of hydrophobic solute in water is, generally, positive but small since there is less free space in the co-sphere of a hydrophobic solute in water. The relatively larger values of $\bar{E}_{2}^{0}$ are thus expected for a solute in a hydrocarbon solvent where there is relatively more free space in the vicinity of a hydrophobic solute in water. The result of our studies shows that the values of $\bar{E}_{2}^{0}$ of CTAB in alcohol-water system are smaller than its value in water. It is expected that increase of temperature reduce the hydrophobic hydration of both alcohol molecules and surfactant monomers, which results an increase in alcohol-surfactant interactions. It is very likely that some of the alcohol molecules may occupy the hydrocarbon part of the micelle, which reduces the free space in the micellar aggregates.

The values of $\bar{E}_{2}^{0}$ (mic) 1-propanol, cyclohexanol and BE in CTAB solution of different concentration are positive and the magnitude are considerably larger than the values in water. This suggests that these molecules, in general, have some hydrocarbon-like environment where there is more free space than in the vicinity of a hydrophobic solute in water, thereby giving higher expansibility. A close agreement between $\bar{E}_{2}^{0}$ (mic) and $\bar{E}_{2}^{0}$ (n-heptane) for cyclohexanol and BE supports this agreement. The variation of $\bar{E}_{2}^{0}$ (mic) with increasing surfactant concentrations, however, does not occur in a consistent manner. The values of $\bar{E}_{2}^{0}$ (mic) for 1-Propanol and BE decreases with increasing surfactant concentration while for cyclohexanol it increases with increasing surfactant concentration. Generally, micelles at high surfactant concentration are less hydrated. The relatively smaller values of $\bar{E}_{2}^{0}$ (mic) for 1-Propanol and BE when the $\mathrm{CTAB}$ concentration is increased to $0.30 \mathrm{~m}$ and $0.35 \mathrm{~m}$ respectively indicate that those molecules are probably located at the surface region of the non- spherical micelle where the hydration effect reduce the expansibilities. The relatively larger values of $\bar{E}_{2}^{0}$ (mic) at low surfactant concentration may be due to a decrease in the amount of electrostricted water in and around the head group of the micelle. In general, the values of $\bar{E}_{2}^{0}$ (mic) indicate that all the alcohols experience a mixed environment in the surfactant solution and are preferentially solubilized close to the micellar surface in the palisade layer. Nevertheless, all these results are generally consistent with the analysis based on the interpretation of volumes and viscosity data. ${ }^{22}$

\section{Acknowledgement}

The authors are grateful to University Grant Commission (UGC) of Bangladesh for providing financial assistance for this work. 


\section{References}

1. J.-H Qian and R. Guo, Colloid polym. Sci., 2004, 282, 979.

2. J.-H Qian, R. Guo and X. Guo, Colloids and Surfaces A., 2003, 215, 253.

3. J.-H Qian, R. Guo and A. H. Zhou, J. Disp. Sci. Tech., 2001, 22, 441.

4. J. A Molina-Bolivar, J. Aguiar and C. C. Ruiz, Molecular Physics., 2001, 99, 1729.

5. V. A. O. Tiera, M. J. Tiera and M. G. Neumann, J. Disp. Sci,. Tech., 2001, 22, 177.

6. C. D. S Rodrigo, and L. Watson, J Colloid and Interface Sci., 1998, 202, 385.

7. M Almgren, Biochimica et Biophysica Acta., 2000, 1508, 146.

8. M.Villeneuve, N. Ikeda, K. Motomura and M. Aratono, J. Colloid and Interface Sci. 1998, 208, 388.

9. N. K Pandit, and J. Kanjia, International J. of Pharmaceutics, 1996, 141, 197.

10. G .Roux-Desgranges, A. H. Roux,J. P.Grolier and A. Viallard, J. Solution Chem. 1982, 1, 357.

11. G. Perron., R. Delisi, I. Davidson, S .Genereus and J. E. Desnoyers, J. Colloid Interface Sci, 1981, 79, 432.

12. R. DeLisi, S . Milioto, M .Castagnolo and A .Inglese, J. Solution Chem., 1990, 19, 767.

13. R .DeLisi, S. Milioto and R. Triolo, J. Solution Chem., 1988, 17, 673.

14. C. Treiner, A. K Chattopadhyay and R. Bury, J. Colloid interface Sci., 1985, 104, 569.

15. F Quirion and J. E desnoyers, J. Colloid Interface Sci, 1986, 112, 565.

16. P Ekwall, L Mandell and P Solyom, J. Colloid Interface Sci, 1971, 35, 519.

17. I. Vikholm, G. Douheret, S. Backlund, Haqiland, J. Colloid Interface Sci., 1987, 116, 582.

18. M. Alauddin and T. Parvin, J. of Applied Science and Technology, 2007, 05(01), 100.

19. Jashim Uddin, M. Sc. Thesis, Chittagong University, 1995, 51.

20. Tasreen Akhter, M. Sc. Thesis, Chittagong University, 1992, 19.

21. W. Reed, M. J. Politi and J. H. fendler, J. Am. Chem. Soc. 1981, 103, 4591.

22. M. Alauddin and T. Parvin, J. of Applied Science and Technology, 2007, 05(01), 100-105. 